\title{
Predictive Value of Small Dense Low-density Lipoprotein Cholesterol for Cardiovascular Events in Chinese Elder Diabetes Mellitus Patients
}

Li Xu

Soochow University

\section{Xu Chen}

Soochow University

Jingfen Lu

Soochow University

Yan Xu

Soochow University

Honglin Yang

Soochow University

Xuewen Zhou

Soochow University

Jianhong Xu

Soochow University

Hao shen ( $\nabla$ shenhaojyk@126.com )

nantong https://orcid.org/0000-0002-5776-7187

\section{Research}

Keywords: Cardiovascular event, Small dense low-density lipoprotein cholesterol, Receiver operating characteristic curve, Diabetes mellitus

Posted Date: February 23rd, 2021

DOl: https://doi.org/10.21203/rs.3.rs-225502/v1

License: (c) (i) This work is licensed under a Creative Commons Attribution 4.0 International License.

Read Full License 


\section{Abstract}

\section{Background}

As a subcomponent of lipoprotein cholesterol (LDL-C), small dense LDL-C (sdLDL-C) has been suggested to be a better predictor of cardiovascular diseases (CVD). The aim of this research was to evaluate the predictive value of the sdLDL-C in cardiovascular events (CVs) in Chinese elder type 2 diabetes mellitus (DM) patients.

\section{Methods}

A total of 386 consecutive type 2 DM patients were included into this study during December 2014 to December 2016. The serum sdLDL-C level of each subject was measured by homogeneous method. During a period of 48-month's follow-up, the occurrence of CVs and associated clinical information were recorded. Receiver operating characteristic (ROC) curves were used to assess the predictive value of serum sdLDL-C to occurrence of major CVs.

\section{Results}

A total of $92 \mathrm{CVs}$ occurred during the study period. The ROC curve analysis manifested that sdLDL-C in the study population had a matchable discriminatory power (AUC for sdLDL-C was $0.7366, P=0.003$ ). In addition, Kaplan-Meier event-free survival curves displayed an obvious increase of CVs risk for sdLDL$\mathrm{C} \geqq 26 \mathrm{mg} / \mathrm{dL}$ (log-rank $=9.10 \bigotimes \mathrm{P}=0.003$ ). This phenomenon had analogous results in patients who received statins at baseline (log rank $=7.336 \otimes P=0.007)$. Cox regression analysis revealed that the increase in HbA1c, glucose, LDL-C, sdLDL-C, non-HDL-C and ApoB and the decrease in ApoAl were obviously interrelated with heightened $\mathrm{CVs}$ risk. Multiple Cox regression demonstrated that the increase of sdLDL-C and $\mathrm{HbA} 1 \mathrm{c}$ was significantly correlated with $\mathrm{CVs}$. The results of the study indicated that high sdLDL-C level $(\mathbb{1 0} \mathrm{mg} / \mathrm{dL})$ was a risk factor for CVs in the multivariate model (HR $1.281,95 \% \mathrm{Cl} 1.225-$ 16.032; $P<0.01)$.

\section{Conclusion}

sdLDL-C level could be an effective predictor in predicting the future CVs for Chinese elder type 2 DM patients with dyslipidemia.

\section{Background}

Type 2 diabetes mellitus (DM) patients are more likely to have cardiovascular disease (CVD) partially due to dyslipidemia characterized by elevated low-density lipoprotein cholesterol (LDL-C), small dense LDL$\mathrm{C}$ (sdLDL-C) and remnant lipoprotein cholesterol (RLP-C) in serum[1, 2]. Moreover, previous researches had discovered that higher sdLDL-C and RLP-C levels were associated with elevated risk of CVD events [3-5]. 
A cross-sectional study has shown that sdLDL-C concentration was closely related to the severity of cardiovascular disease and was independent of classic coronary risk factors [6]. Moreover, another study has revealed that a higher RLP-C concentration was a risk factor for cardiovascular events (CVs) independent of other risk factors in diabetic patients [7]. However, few studies in the past have assessed the relationship between sdLDL-C and RLP-C and CVs in Chinese elder type 2 diabetes mellitus (DM) patients.

The serum SdLDL-C level could be easily detected through automated analysis [8]. However, these methods have not yet been impressed on large number of type 2 DM patients, especially among the Chinese elder population. The study attempted to investigate whether sdLDL-C can predict CVs in Chinese elder type 2 DM patients.

\section{Methods}

\section{Subjects and study design}

This research included 418 consecutive patients aged $\geq 65$ years with type 2 DM at Suzhou Ninth People's Hospital, Suzhou, China, between December 2014 and December 2016, and all of the subjects had no history of CVD. DM was identified according to 2009 American Diabetes Association Criteria for diabetes diagnosis [9]. The body mass index (BMI), estimate of glomerular filtration rate (eGFR) and smoking status (current smokers and at least one cigarette per day) were recorded. The diagnosis of hypertension was based on blood pressure measurement (systolic blood pressure $\geq 140 \mathrm{mmHg}$ and/or diastolic blood pressure $\geq 90 \mathrm{mmHg}$ ) and/or use of antihypertensive medications within 2 weeks of enrollment[10]. Dyslipidemia was defined as the fasting serum LDL-C $\geq 140$ (mg/dl), high-density lipoprotein cholesterol (HDL-C) $<40(\mathrm{mg} / \mathrm{dL})$ or triglyceride $(\mathrm{TG}) \geq 150(\mathrm{mg} / \mathrm{dL})$ and/or the current use of lipid-lowering medication [11]. Exclusion criteria were: age $\geq 90$ years $(n=2)$, presence of malignancy $(n=$ $3)$, known thyroid disorders $(n=3)$, lost of blood examination data $(n=6)$, infectious disease $(n=7)$, lost during follow-up $(n=7)$ and severe hepatic and nephrotic diseases $(n=4)$.

Finally, a total of 386 patients (mean age of $72.7 \pm 5.4$ year, range from 65 to 86 years) were included into the study (269 males and 117 females). They received follow-ups ranging from 20 to 48 months, with an average of 28 months. Blood biochemical examinations were performed for subjects yearly during the follow-up period. The associated clinical and laboratory data was collected between September and November 2019. The endpoints were: (1) CVD death, (2) the date of the first occurrence of CVs, and (3) the date of the patient's last visit to Suzhou Ninth People's Hospital. CVs were difined as (1) death caused by cardiovascular disease, (2) onset of acute coronary syndrome, (3) congestive heart failure, (4) need for coronary or other arterial revascularization, (5) stroke and registered in Table 1. 
Table 1

Cardiovascular events were defined and registered during the follow-up

\begin{tabular}{|ll|}
\hline Cardiovascular events defined & Registered $(\mathbf{n}=\mathbf{9 2})$ \\
\hline Death caused by cardiovascular disease & 8 \\
\hline Onset of acute coronary syndrome & 13 \\
\hline Congestive heart failure & 26 \\
\hline Need for coronary or other arterial revascularization & 36 \\
\hline Stroke & 9 \\
\hline
\end{tabular}

\section{Laboratory measurements}

The blood samples were collected after 12 hours of fasting in the morning. After collection, the samples were centrifuged immediately and stored at $-80^{\circ} \mathrm{C}$ until assay within the same day. High-sensitivity Creactive protein(hsCRP), HDL-C, Hemoglobin A1c (HbA1c), LDL-C, TG, fasting blood glucose, apolipoprotein $A-I(A p o A-I)$, apolipoprotein $B \square A p o B \square$ and lipoprotein (a) were detected through standard biochemical tests as reported previously[12]. The sdLDL-C and RLP-C were detected by a detergent-based fully-automatic homogeneous method (Denka Seiken kit, Tokyo,Japan)[5, 13].

\section{Statistical analyses}

All statistical analyses were performed using the SAS 9.1 solftware package. The Chi-square test was used to analyze categorical variables. Wilcoxon test and independent student $t$-test was used to compare the means between the CVs group and non-CVs group. Correlation coefficients between sdLDL-C and other parameters were determined by Spearman's rank analysis. Kaplan-Meier method was used to compare the occurrence of CVs between the lower sdLDL-C and higher sdLDL-C group, and the differences were assessed with log-rank test. The receiver operating characteristic (ROC) curves and area under the curve (AUC) were used for assess the ability of sdLDL-C, HbA1c, and RLP-C to predict CVs. Cox regression and multivariate Cox regression analysis were employed to determine these independent predictors. All statistical analyses were double-tailed, and statistical significance was considered at the level of $\mathrm{P}<0.05$.

\section{Results}

The occurrences of CVs were summarized in Table 1. The patients with CVs had obviously higher BMI and were more likely to be under calcium channel blockers and insulin therapy compared with non-CVs patients (Table 2). A comparison of laboratory findings manifested the levels of glucose, HbA1C,LDL-C, non-HDL-C, sdLDL-C, RLP-C, ApoB and ApoA-1 in the CVs group were significantly different from those of the non-CVs group (Table 3). Whereas there was no statistically significant difference in TG, hsCRP, HDLC, eGFR, sdLDL-C /LDL-C ratioand lipoprotein (a) between the two groups. 
Table 2

The clinical characteristics of the enrolled patients at baseline

\begin{tabular}{|c|c|c|c|c|}
\hline \multirow[t]{2}{*}{ Variables } & Whole & CVs & non-CVs & \multirow[t]{2}{*}{$P^{a}$} \\
\hline & $(n=386)$ & $(n=92)$ & $(n=294)$ & \\
\hline \multicolumn{5}{|l|}{ Characteristics } \\
\hline Age (years) & $72.7 \pm 5.4$ & $72.9 \pm 5.2$ & $72.8 \pm 5.5$ & 0.568 \\
\hline Male & 269/386 (69.7) & $65 / 92(70.6)$ & 204/294 (69.4) & 0.818 \\
\hline $\mathrm{BMI}\left(\mathrm{kg} / \mathrm{m}^{2}\right)$ & $23.6 \pm 2.1$ & $24.3 \pm 2.3$ & $23.4 \pm 2.2$ & 0.001 \\
\hline \multicolumn{5}{|c|}{ Cardiovascular disease risk factors } \\
\hline Hypertension & 270/386 (69.9) & $64 / 92(69.6)$ & 206/294 (70.1) & 0.927 \\
\hline Dyslipidemia & $246 / 386(90.2)$ & $83 / 92(90.2)$ & 265/294 (90.1) & 0.982 \\
\hline Smoking, current or former & $246 / 386(63.7)$ & $59 / 92(64.1)$ & 187/294 (63.6) & 0.927 \\
\hline Family history & $82 / 386(21.2)$ & $21 / 92(22.8)$ & $61 / 294(20.7)$ & 0.671 \\
\hline \multicolumn{5}{|l|}{ medications } \\
\hline Calcium-channel blocker & $165 / 386(42.7)$ & 48/92 (52.2) & 117/294 (39.8) & 0.036 \\
\hline ACEl & 212/386 (54.9) & $56 / 92(60.9)$ & 156/294 (53.1) & 0.189 \\
\hline ARB & $172 / 386(14.8)$ & $40 / 92(43.5)$ & $132 / 294(44.9)$ & 0.943 \\
\hline$\beta$-blocker & $114 / 386(44.5)$ & 27/92 (29.3) & $87 / 294(29.6)$ & 0.964 \\
\hline Aspirin & $347 / 386(89.9)$ & $84 / 92(91.3)$ & 263/294 (89.5) & 0.608 \\
\hline Insulin & $27 / 386(7.0)$ & $12 / 92(13.0)$ & $15 / 294(5.1)$ & 0.009 \\
\hline Statin & $224 / 386(58.0)$ & $47 / 92(51.1)$ & $162 / 294(55.1)$ & 0.501 \\
\hline \multicolumn{5}{|c|}{$\begin{array}{l}\text { Data are presented as mean mean } \pm \text { SD or the number and its percentage }(\%) \text { percentage }=\text { the number } \\
\text { of each individual category divided by } \mathrm{n} \text { CVs, cardiovascular events; BMI body mass index; ACEI, } \\
\text { angiotensin-converting enzyme inhibitor; ARB, angiotensin-receptor blocker }\end{array}$} \\
\hline \multicolumn{5}{|c|}{${ }^{\mathrm{a}}$ Indicates the comparison of mean or percentage between CVs group and non-CVs group } \\
\hline
\end{tabular}


Table 3

The laboratory characteristics of the enrolled patients at baseline

\begin{tabular}{|c|c|c|c|c|}
\hline \multirow[t]{2}{*}{ Variables } & \multirow{2}{*}{$\begin{array}{l}\text { Whole } \\
(n=386)\end{array}$} & \multirow{2}{*}{$\begin{array}{l}\text { CVs } \\
(n=92)\end{array}$} & \multirow{2}{*}{$\begin{array}{l}\text { non-CVs } \\
(n=294)\end{array}$} & \multirow[t]{2}{*}{$P^{a}$} \\
\hline & & & & \\
\hline Triglycerides (mg/dL) & $123.6 \pm 71.3$ & $134.5 \pm 88.3$ & $120.3 \pm 63.2$ & 0.097 \\
\hline LDL-C (mg/dL) & $107.9 \pm 30.5$ & $116.7 \pm 29.9$ & $105.1 \pm 29.8$ & 0.001 \\
\hline sdLDL-C (mg/dL) & $31.0 \pm 12.1$ & $36.2 \pm 15.2$ & $29.4 \pm 16.8$ & 0.001 \\
\hline HDL-C (mg/dL) & $46.8 \pm 15.1$ & $44.2 \pm 12.9$ & $47.6 \pm 15.1$ & 0.052 \\
\hline Non-HDL-C (mg/dL) & $129.3 \pm 34.1$ & $138.3 \pm 35.5$ & $126.5 \pm 33.4$ & 0.004 \\
\hline sdLDL-C/LDL-C & $0.29 \pm 0.11$ & $0.31 \pm 0.13$ & $0.28 \pm 0.16$ & 0.102 \\
\hline RLP-C(mg/dL) & $5.0 \pm 3.1$ & $5.6 \pm 3.5$ & $4.8 \pm 2.7$ & 0.022 \\
\hline Glucose (mg/dL) & $114.9 \pm 34.5$ & $122.6 \pm 46.4$ & $112.5 \pm 29.5$ & 0.014 \\
\hline $\mathrm{HbA1c}(\%)$ & $6.38 \pm 1.2$ & $6.8 \pm 1.3$ & $6.25 \pm 1.09$ & 0.001 \\
\hline ApoA-I (mg/dL) & $125.0 \pm 25.3$ & $119.3 \pm 23.6$ & $126.8 \pm 27.1$ & 0.018 \\
\hline ApoB (mg/dL) & $86.1 \pm 21.3$ & $92.1 \pm 21.6$ & $84.2 \pm 22.1$ & 0.003 \\
\hline $\operatorname{eGFR}\left(\mathrm{mL} / \mathrm{min} / 1.73 \mathrm{~m}^{2}\right)$ & $69.9 \pm 19.2$ & $68.8 \pm 14.1$ & $70.3 \pm 15.6$ & 0.411 \\
\hline $\mathrm{hsCRP}(\mathrm{mg} / \mathrm{dL})$ & $0.54 \pm 1.1$ & $0.53 \pm 1.3$ & $0.55 \pm 0.98$ & 0.875 \\
\hline $\mathrm{Lp}(\mathrm{a})(\mathrm{mg} / \mathrm{dL})$ & $22.9 \pm 24.1$ & $25.1 \pm 25.2$ & $22.3 \pm 24.1$ & 0.401 \\
\hline \multicolumn{5}{|c|}{$\begin{array}{l}\text { Data are presented as mean mean } \pm \text { SD. LDL-C, low-density lipoprotein cholesterol; sdLDL-C, small } \\
\text { dense low-density lipoprotein cholesterol; HDL-C, high-density lipoprotein cholesterol;RLP-C, remnant } \\
\text { lipoprotein cholesterol;HbA1c, hemoglobin A1C; ApoA-l, apolipoprotein A-l; ApoB, apolipoprotein B; } \\
\text { eGFR, estimated glomerular fifiltration rate;hsCRP, high-sensitivity C-reactive protein;Lp (a), lipoprotein } \\
\text { (a) }\end{array}$} \\
\hline
\end{tabular}

In this study, first-time CVs were observed in 92 patients. Kaplan-Meier method showed an obvious increase of CVs risk for the median levels of sdLDL-C (Fig. 1a). Similar trend was found in patients who received statins (Fig. 1b). Cox regression analysis showed that increase in sdLDL-C and HbA1c was associated with a higher risk for CVs (Table 4). To determine whether sdLDL-C was an independent risk factor, we performed Cox multivariate regression analysis. The models were built after adjustment age, gender and CVs risk factors. Model 1 (including Glucose, HbA1c, LDL-C, Non-HDL-C,sdLDL-C, ApoA-I and ApoB) and Model 2 (only including sdLDL-C and HbA1c) showed that just sdLDL-C and $\mathrm{HbA} 1 \mathrm{c}$ remained significantly associated with the risk of CVs. These results suggest that elevated Glucose and dyslipidemia might contribute to CVs. 
Table 4

Predictors for cardiovascular events according to Cox,s proportional hazard analysis

\begin{tabular}{|c|c|c|c|}
\hline \multirow[t]{3}{*}{ variable } & Univariate model & \multicolumn{2}{|c|}{ Multivariate model } \\
\hline & \multirow[t]{2}{*}{$\mathrm{HR} \quad 95 \% \mathrm{Cl}$} & Model 1 & Model 2 \\
\hline & & $\mathrm{HR} \quad 95 \% \mathrm{Cl}$ & $\mathrm{HR} \quad 95 \% \mathrm{Cl}$ \\
\hline Age & $1.065(1.136-1.624)^{\star \star}$ & $1.034(1.015-1.583)^{\star}$ & 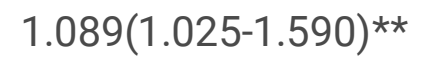 \\
\hline Gender (Men) & $0.801(0.456-1.564)$ & $0.771(0.469-1.693)$ & $0.774(0.501-1.763)$ \\
\hline LDL-C (per 10 mg/dL) & $1.103(1.093-1.347)^{\star \star}$ & 1.135 (0.857-1.432) & - \\
\hline sdLDL-C (per 10 mg/dL) & $\begin{array}{l}1.285(1.145- \\
19.033)^{\star *}\end{array}$ & $\begin{array}{l}1.276(1.201- \\
16.664)^{* *}\end{array}$ & $\begin{array}{l}1.281(1.225- \\
16.032)^{\star *}\end{array}$ \\
\hline $\begin{array}{l}\text { Non-HDL-C (per } 10 \\
\text { mg/dL) }\end{array}$ & $1.089(1.038-1.945)^{\star \star}$ & $1.131(0.955-1.836)$ & - \\
\hline RLP-C & $1.165(0.873-2.055)$ & - & - \\
\hline Glucose & $1.107(1.066-1.208)^{\star}$ & $0.996(0.905-1.202)$ & - \\
\hline $\mathrm{HbA1c}$ & $1.305(1.13-2.312)^{\star \star \star}$ & 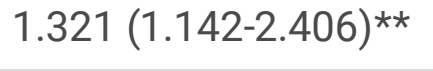 & $1.225(1.152-2.412)^{\star \star}$ \\
\hline ApoA-I (per 10 mg/dL) & $0.889(0.762-0.941)^{\star \star}$ & $0.892(0.798-1.042)$ & - \\
\hline ApoB (per 10 mg/dL) & $1.125(1.095-2.055)^{\star \star}$ & $0.796(0.718-1.944)$ & - \\
\hline \multicolumn{4}{|c|}{$\begin{array}{l}{ }^{*} \mathrm{P}<0.05,{ }^{* *} \mathrm{p}<0.01, \text {,**} \mathrm{p}<0.001 \text {.LDL-C, low-density lipoprotein cholesterol; sdLDL-C, small dense low- } \\
\text { density lipoprotein cholesterol; HDL-C, high-density lipoprotein cholesterol;RLP-C, remnant lipoprotein } \\
\text { cholesterol;HbA1 c, hemoglobin A1c; ApoA-l, apolipoprotein A-l; ApoB, apolipoprotein B }\end{array}$} \\
\hline $\begin{array}{l}\text { The step-wise Cox regre } \\
\text { independent predictors }\end{array}$ & and multivariate Cox & ession analysis we & d to regulate these \\
\hline
\end{tabular}

Spearman's correlation analysis suggested that compared with LDL-C, the serum level of sdLDL-C exhibited more significant correlations with various parameters,suggesting that sdLDL-C might the major factor among LDL-C contribute to CVs.

We performed the ROC analysis in order to test the discriminatory power of sdLDL-C for the CVs (Fig. 2). The result indicate that the AUC of the sdLDL-C has a strong discriminating power against CVs, and its optimal cut-off value is $36.2 \mathrm{mg} / \mathrm{dL}(\mathrm{AUC}=0.736, \mathrm{P}=0.003)$ than $\mathrm{HbA} 1 \mathrm{C}$ and $\mathrm{RLP}-\mathrm{C}$.

\section{Discussion}

Diabetes mellitusis patients are often accompanied by dyslipidemia, which is the major controllable risk factor associated with cardiovascular disease (CVD) events. Dyslipidemia has been confirmed as one of 
the principal processes underlying CVD, while sdLDL-C is considered as an emerging risk factor for CVD. Indeed, about 70\% of elder type 2 DM patients die from CVD [14-16].

Previous studies concerning the elevated levels of sdLDL-C has been associated with CVs [17-19]. However, to the best of our knowledge, few studies have investigated on the influence of sdLDL-C levels on the onset of CVs in Chinese elderly type2 DM patients.

In the present study, Spearman's rank correlation analysis suggest that sdLDL-C might the major factor among LDL-C contribute to CVs. Fourthermore, ROC curve assay indicated that the AUC of the sdLDL-C has a strong discriminating power against $\mathrm{CVs}$, and its optimal cut-off value is $36.2 \mathrm{mg} / \mathrm{dL}$ ( $A U C=0.736$, $P=0.003$ ) than HbA1C and RLP-C(Fig. 2). Kaplan-Meier event-free survival curve displayed a obvious increase of CVs risk for the median levels of sdLDL-C(Fig. 1a). This phenomenon had analogous results in patients who received statins at baseline(Fig. 1b). Cox regression analysis showed that increase in sdLDL-C and HbA1c revealed a higher risk for CVs. From the Table 5, we do see the correlation between sdLDL-C and RLP-C, but in the multivariable model, the RLP-C variable has been excluded from the regression automatically because less correlation with the outcome compare to sdLDL-C (Table 4).

Table 5

Spearman's correlation of LDL-C and sdLDL-C to $1000 \mathrm{um}$

\begin{tabular}{|c|c|c|c|c|}
\hline \multirow[t]{2}{*}{ Variables } & \multicolumn{2}{|l|}{ LDL-C } & \multicolumn{2}{|c|}{ sdLDL-C } \\
\hline & $\mathbf{r}$ & $\mathbf{P}$ & $\mathbf{r}$ & $\mathbf{P}$ \\
\hline age & -0.194 & 0.009 & -0.164 & 0.025 \\
\hline Triglycerides & 0.171 & 0.018 & 0.323 & 0.001 \\
\hline HDL-C & -0.029 & 0.702 & -0.363 & 0.001 \\
\hline Non-HDL-C & 0.563 & 0.001 & 0.588 & 0.001 \\
\hline RLP-C & 0.406 & 0.011 & 0.521 & 0.001 \\
\hline $\mathrm{HbA1c}$ & 0.024 & 0.802 & 0.061 & 0.431 \\
\hline ApoA-I & -0.035 & 0.704 & -0.301 & 0.001 \\
\hline ApoB & 0.622 & 0.001 & 0.623 & 0.001 \\
\hline $\operatorname{Lp}(a)$ & 0.252 & 0.008 & 0.027 & 0.831 \\
\hline \multicolumn{5}{|c|}{$\begin{array}{l}\text { LDL-C, low-density lipoprotein cholesterol; sdLDL-C, small dense low-density lipoprotein cholesterol; } \\
\text { HDL-C, high-density lipoprotein cholesterol;RLP-C, remnant lipoprotein cholesterol;HbA1c, hemoglobin } \\
\text { A1c; ApoA-l, apolipoprotein A-l; ApoB, apolipoprotein B;Lp (a), lipoprotein (a) }\end{array}$} \\
\hline \multicolumn{5}{|c|}{ For the variable not follow normal distribution, Spearman's rank correlation usually will be use } \\
\hline
\end{tabular}


To determine whether sdLDL-C was an independent risk factor, we use the step-wise COX regression, even if the correlated variables are included, some of them will be excluded from the model automatically if they are not relevant compared to the investigational factor. The models were built after adjustment age, gender and CVs risk factors. Model 1 including Glucose, HbA1c, LDL-C, Non-HDL-C,sdLDL-C, ApoA-I and ApoB and Model 2 only including sdLDL-C and HbA1c showed that just sdLDL-C and HbA1c remained significantly associated with the risk of CVs These results suggest that elevated Glucose and dyslipidemia might contribute to CVs.

Indeed, sdLDL-C levels has the ability to predict CVD better than total LDL-C[18].In addition, the Québec Cardiovascular Study has shown that sdLDL-C is interrelated with an raised risk of CAD in men.[6, 7] On the other hand, remnant lipoproteins are rich in TG and the main components include VLDL in the fasting state[20].Obviously, the current study not only confirmed the sdLDL-C concentrations was an independent risk predictor for $\mathrm{CVs}$, but also provided novel information concerning the role of RLP-C in predicting CVs in diabetic patients[21-24].

There are some limitations in this cohort study: First, the sample size is small and all the patients are Chinese, which may lead to a bias to fully observe the results and/or severity of CAD. Second, of all the lipid biomarkers, only sdLDL-C was found independently associated with CVs among elder diabetes mellitus patients; whether it is because of the effect of statin therapy needs further investigation. Finally, the comparison of the predictive ability of sdLDL-C for CVs to the patient subgroup needs further research.

\section{Conclusion}

The current study demonstrated that sdLDL-C was an effective predictor in predicting the future CVs of elderly diabetic patients with dyslipidemia.

\section{Abbreviations}

DM: diabetes mellitus;

CVs: cardiovascular events;

CVD: cardiovascular diseases;

sdLDL-C: small dense low-density lipoprotein cholesterol;

RLP-C: remnant lipoprotein cholesterol;

LDL-C: low-density lipoprotein cholesterol;

HDL-C: high-density lipoprotein cholesterol; 
HbAlc: hemoglobin A1c;21-24

Apo: apolipoprotein;

Lp (a): lipoprotein (a);

ROC curves: receiver operating characteristic curves

\section{Declarations}

\section{Acknowledgements}

This study was supported by Department of Clinical Laboratory Medicine, Suzhou Ninth People's Hospital, Suzhou, China.

\section{Funding}

Fifth Batch of Gusu Health Personnel Project(GSWS2019087).

\section{Ethics approval and consent to participate}

This study was approved by the Committee on Human Research of Suzhou Ninth People's Hospital. All patients signed a dedicate informed consent.

\section{Availability of data and materials}

Unfortunately, the initial data cannot be shared as it contains confidential information.

\section{Consent for publication}

Not applicable.

\section{Competing interests}

The authors declare no conflicts of interest.

\section{Authors' contributions}

$\mathrm{XL}$ and $\mathrm{CX}$ planned the study and wrote the manuscript. LJF, XY and YHL contributed to data collection and enrolled patients. ZXW performed the flow mediated dilatation test. XJH and SH supervised the study and reviewed/edited the manuscript.

\section{References}

1. Hirano T. Pathophysiology of Diabetic Dyslipidemia. J Atheroscler Thromb. 2018; 25: 771-82 . 
2. Brannick B , Dagogo-Jack S. Prediabetes and Cardiovascular Disease: Pathophysiology and Interventions for Prevention and Risk Reduction. Endocrinol Metab Clin North Am. 2018; 47: 33-50.

3. Ai M, Otokozawa S, Asztalos BF, Ito Y, Nakajima K, White CC, Cupples LA, Wilson PW, and Schaefer EJ: Small dense LDL cholesterol and coronary heart disease: results from the Framingham Offspring Study. Clin Chem. 2010; 56: 967-76.

4. Saeed A, Feofanova EV, Yu B, Sun W, Virani SS, Nambi V, Coresh J, Guild CS, Boerwinkle E, Ballantyne $\mathrm{CM}$, and Hoogeveen RC: Remnant-Like Particle Cholesterol, Low-Density Lipoprotein Triglycerides, and Incident Cardiovascular Disease. J Am Coll Cardiol. 2018; 72: 156- 69.

5. Tsai MY, Steffen BT, Guan W, McClelland RL, Warnick R, McConnell J, Hoefner DM, and Remaley AT: New automated assay of small dense low-density lipoprotein cholesterol identifies risk of coronary heart disease: the Multi-ethnic Study of Atherosclerosis. Arterioscler Thromb Vasc Biol. 2014; 34: 196-201.

6. Hoogeveen RC, Gaubatz JW, Sun W, Dodge RC, Crosby JR, Jiang J, Couper D, Virani SS, Kathiresan S, Boerwinkle E, and Ballantyne CM: Small dense low-density lipoprotein-cholesterol concentrations predict risk for coronary heart disease: the Atherosclerosis Risk In Communities (ARIC) study. Arterioscler Thromb Vasc Biol. 2014; 34: 1069-77.

7. St-Pierre AC, Cantin B, Dagenais GR, Mauriège P, Bernard P-M, Després J-P, Lamarche B. Low-Density Lipoprotein Subfractions and the Long-Term Risk of Ischemic Heart Disease in Men. Arterioscler Thromb Vasc Biol, 2005; 25: 553-59.

8. Hirano T, Ito Y, Saegusa H, Yoshino G: A novel and simple method for quantification of small, dense LDL. J Lipid Res. 2003; 44: 2193-201.

9. American Diabetes Association. Executive summary: standards of medical care in diabetes-2011. Diabetes Care. 2011;34(Suppl 1):S4-10.

10. Chobanian AV, Bakris GL, Black HR, Cushman WC, Green LA, Izzo JL, Jr, et al. The seventh report of the joint national committee on prevention, detection, evaluation, and treatment of high blood pressure: the jnc 7report. JAMA. 2003;289:2560-72.

11. Expert Panel on Detection, Evaluation, and Treatment of High Blood Cholesterol in Adults. Executive Summary of The Third Report of The National Cholesterol Education Program (NCEP) Expert Panel on Detection, Evaluation, And Treatment of High Blood Cholesterol In Adults (Adult Treatment Panel III). JAMA. 2001;285:2486-97.

12. Shen H, Zhou J, Shen G, Yang H, Lu Z, Wang H. Correlation between serum levels of small, dense lowdensity lipoprotein cholesterol and carotid stenosis in cerebral infarction patients $>65$ years of age. Ann Vasc Surg. 2014;28:375-80.

13. Ito Y, Hirao Y. Development of a novel homogeneous assay for remnant like particle cholesterol (abstract 484) Atheroscler Suppl. 2011;12:103.

14. Go AS, Mozaffarian D, Roger VL, et al. .; American Heart Association Statistics Committee and Stroke Statistics Subcommittee. Executive summary: heart disease and stroke statistics--2013 update: a report from the American Heart Association. Circulation 2013;127:143-52. 
15. Kannel WB, McGee DL. Diabetes and cardiovascular disease. JAMA (1979) 241:2035-8.

16. Grundy SM, Benjamin IJ, Burke GL, Chait A, Eckel RH, Howard BV, et al. Diabetes and cardiovascular disease: a statement for health professionals from the American Heart Association. Circulation (1999) 100:1134-46.

17. Ito Y, Fujimura M, Ohta M, Hirano T: Development of a homogeneous assay for measurement of small dense LDL cholesterol. CLIN CHEM. 2011; 57: 57-65

18. Arai H, Kokubo Y, Watanabe M, Sawamura T, Ito Y, Minagawa A, Okamura T, and Miyamato Y: Small dense low-density lipoproteins cholesterol can predict incident cardiovascular disease in an urban Japanese cohort: the Suita study. J Atheroscler Thromb. 2013; 20: 195-203

19. Ito Y, Ohta M, Ikezaki H, Hirao Y, Machida A, Schaefer EJ, and Furusyo N: Development and population results of a fully automated homogeneous assay for LDL triglyceride. JALM. 2017; 2: 746-56.

20. Chapman MJ, Ginsberg HN, Amarenco P, Andreotti F, Boren J, Catapano AL, et al. Triglyceride-rich lipoproteins and high-density lipoprotein cho lesterol in patients at high risk of cardiovascular disease: evidence and guidance for management. Eur Heart J. 2011;32:1345-61.

21. Schwartz GG, Abt M, Bao W et al. Fasting triglycerides predict recurrent ischemic events in patients with acute coronary syndrome treated with statins. J Am Coll Cardiol 2015; 65: 2267-75.

22. Masuda D, Yamashita S. Postprandial hyperlipidemia and remnant lipoproteins. J Atheroscler Thromb 2017; 24: 95-109.

23. Kugiyama K, Doi H, Takazoe K et al. Remnant lipoprotein levels in fasting serum predict coronary events in patients with coronary artery disease. Circulation 1999; 99: 2858-60.

24. Nguyen SV, Nakamura T, Kugiyama K. High remnant lipoprotein predicts recurrent cardiovascular events on statin treatment after acute coronary syndrome. Circ J 2014; 78: 2492-500.

\section{Figures}




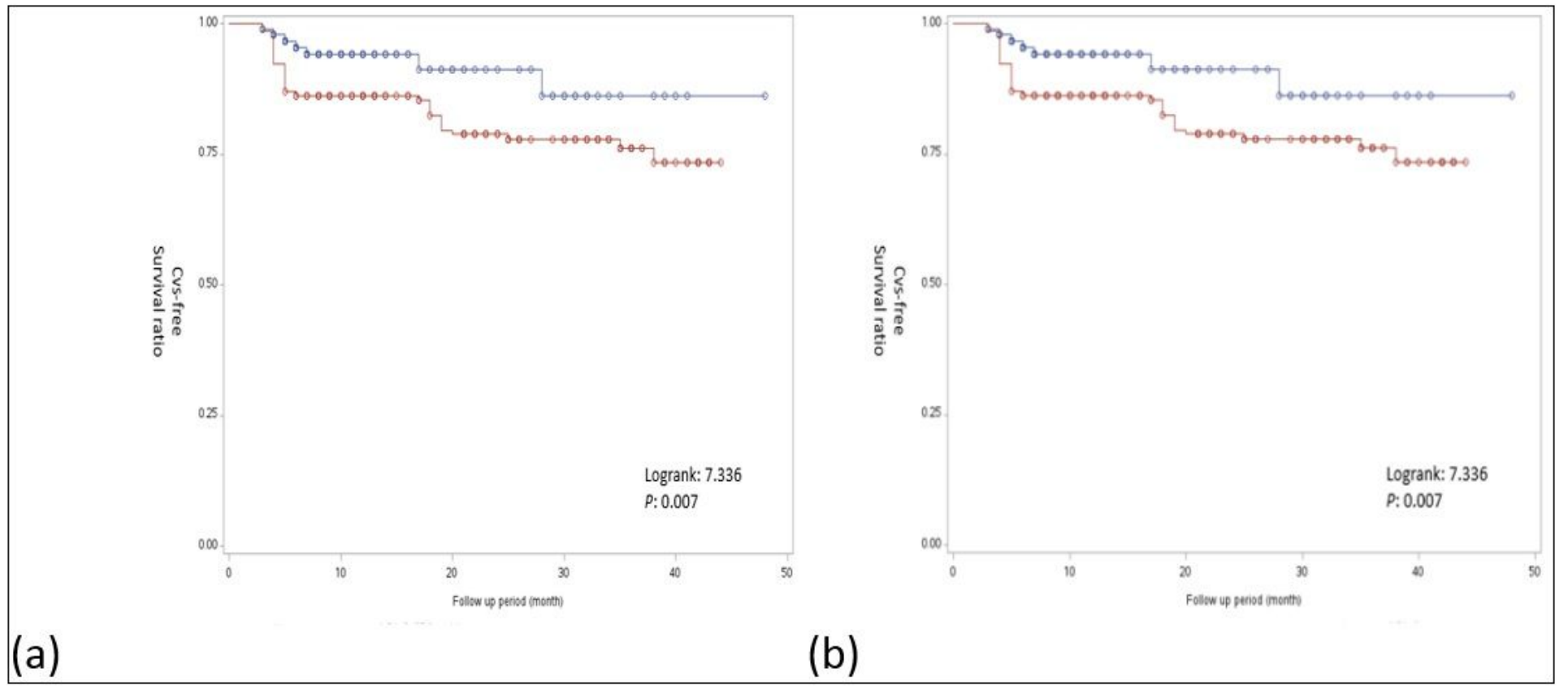

\section{Figure 1}

The Kaplan-Meier eventfree survival of patients stratifified by the median small dense low- density lipoprotein cholesterol (sdLDL-C) concentration (26 mg/dL). (a) All patients, (b) patients treated with statins 


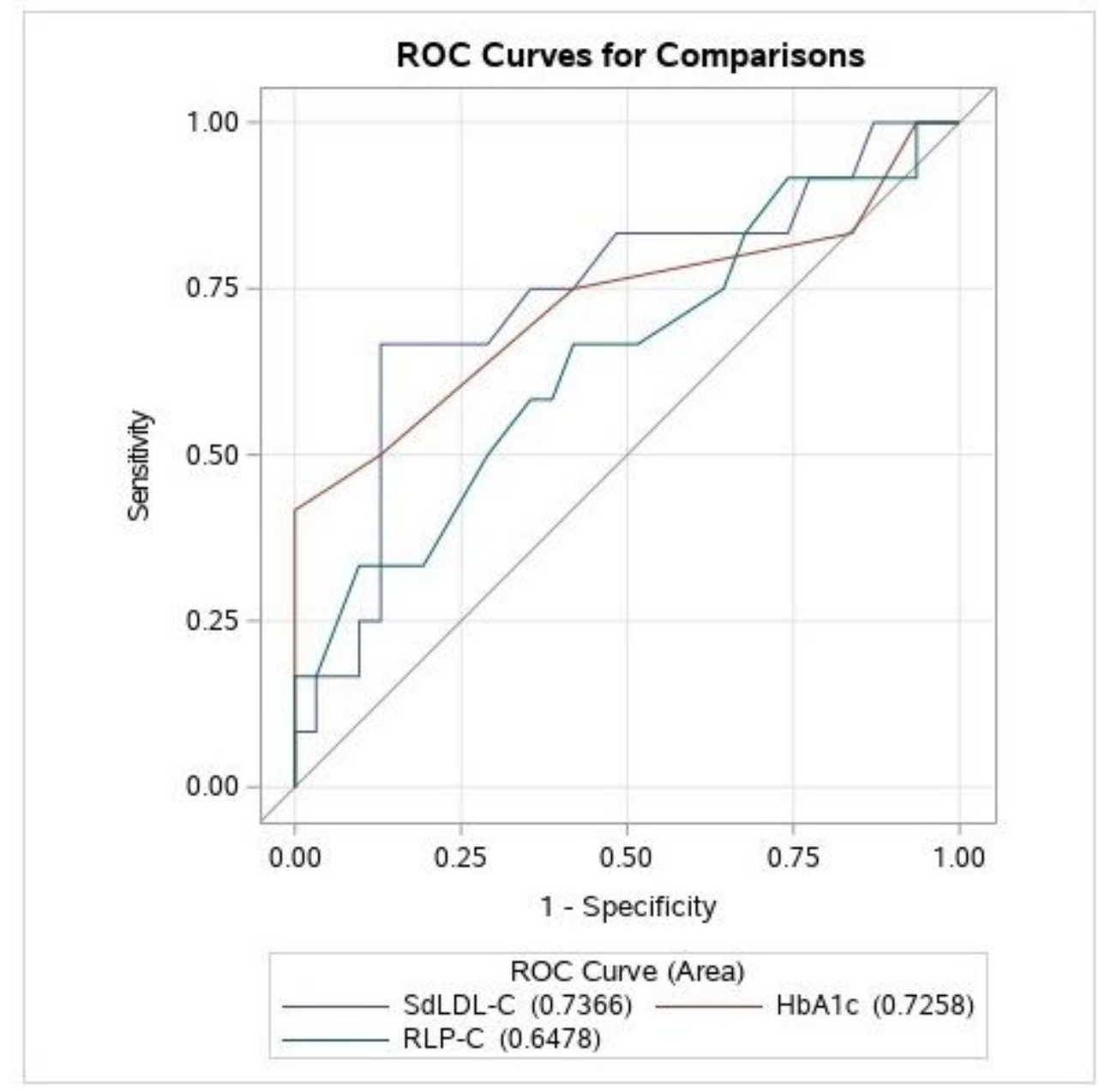

Figure 2

Receiver operating characteristic curves showed discriminatory power of SdLDL-C, HbA1C and RLP-C on cardiovascular events 